\title{
BMJ A randomised cross-over cohort study open of exposure to emissions from a road tunnel ventilation stack
}

Christine T Cowie, ${ }^{1,2}$ Wafaa Ezz, ${ }^{1,2}$ Wei Xuan, ${ }^{1,2}$ William Lilley, ${ }^{3}$ Nectarios Rose, ${ }^{1,4}$ Michael Rae, ${ }^{3}$ Guy B Marks ${ }^{1}$

To cite: Cowie CT, Ezz W, Xuan $\mathrm{W}$, et al. A randomised cross-over cohort study of exposure to emissions from a road tunnel ventilation stack. BMJ Open 2012;00: e001201. doi:10.1136/ bmjopen-2012-001201

- Prepublication history and additional material for this paper are available online. To view these files please visit the journal online (http://dx. doi.org/10.1136/bmjopen2012-001201).

Received 3 April 2012 Accepted 12 July 2012

This final article is available for use under the terms of the Creative Commons Attribution Non-Commercial 2.0 Licence; see http://bmjopen.bmj.com

For numbered affiliations see end of article

\footnotetext{
Correspondence to

Professor Guy B Marks, Respiratory and

Environmental Epidemiology, Woolcock Institute of Medical Research, PO Box M77,

Missenden Road PO, Sydney NSW 2050, Australia, guy. marks@sydney.edu.au
}

\section{ABSTRACT}

Background and objective: Road tunnels are increasingly important components of urban infrastructure. However, knowledge of their health impact on surrounding communities is limited. Our objective was to estimate the short-term respiratory health effects of exposure to emissions from a road tunnel ventilation stack.

Methods: We conducted a randomised cross-over cohort study in 36 volunteers who underwent three exposure scenarios in 2006 before the road tunnel opened, and in $2007(n=27)$ and $2008(n=20)$ after the tunnel opened. Exposure downwind of the stack was compared to upwind of the stack and to a distant heavily trafficked location adjacent to a main road. Spirometry, exhaled nitric oxide (eNO) and symptom scores were measured repeatedly during each $2 \mathrm{~h}$ exposure session. Results: Downwind locations were associated with increased reports of 'dry nose' (score difference 0.36; $95 \% \mathrm{Cl} 0.09$ to 0.63 ) compared with the control location (2006 vs 2007/2008), but not with impaired lung function, increased airway inflammation or other symptoms. The heavily trafficked location was associated with significantly increased eNO (ratio $=1.09 ; 95 \% \mathrm{Cl} 1.04$ to 1.14 ), eye (score difference $0.05 ; 95 \% \mathrm{Cl} 0.01$ to 0.10 ) and chest (score difference $0.21 ; 95 \% \mathrm{Cl} 0.09$ to 0.33 ) symptoms compared to the stack locations.

Conclusions: There was no consistent evidence of adverse respiratory effects from short-term exposures downwind of the tunnel ventilation stack, except for dry nose symptoms. However, the findings of increased airway inflammation and symptoms in subjects after only $2 \mathrm{~h}$ exposure at the heavily trafficked location, are suggestive of detrimental effects of short-term exposures to traffic-related air pollution.

\section{INTRODUCTION}

Road tunnels are increasingly important components of urban infrastructure. However, few studies have investigated the adverse impacts of exposure to emissions from road tunnel portals or their ventilation stacks, or the beneficial effects of diverting traffic from surface roads into tunnels. This may be due to the difficulty

\section{ARTICLE SUMMARY}

Article focus

- Road tunnels are being increasingly commissioned in major cities around the world to alleviate traffic on surface roads.

- There are little existing data on the health impacts of exposure to tunnel emissions on surrounding communities.

- Our objective was to estimate the short-term respiratory health effects of exposure to emissions from a road tunnel ventilation stack.

Key messages

- There was no consistent evidence of adverse respiratory effects of being located downwind of the tunnel ventilation stack, except for an increase in dry nose symptoms.

- Short-term (2 h) exposures to a heavily trafficked control site were associated with increased airway inflammation, eye and chest symptoms.

- The findings suggest detrimental effects of short-term exposure to traffic-related air pollution, but are not supportive of consistent adverse effects from short-term exposures downwind of the tunnel ventilation stacks.

Strengths and limitations of this study

- Strengths of the study include: the randomised cross-over cohort design and blinding of participants; use of a heavily trafficked site as a positive control; the before/after nature of our study; the repeated measures within and across years; and the sensitivity analysis.

- A limitation of our study is the differential loss from the groups over time.

in designing studies that distinguish between emissions from road tunnels and emissions from general surrounding traffic. ${ }^{12}$ Only one study has investigated the association between exposure to emissions from a road tunnel ventilation stack and health effects. That crosssectional study found no evidence of increased respiratory or irritant symptoms in high exposure zones compared to low exposure zones. ${ }^{3}$ 
Several recent studies have reported designs that may be helpful for assessing this type of exposure. Each has investigated the respiratory ${ }^{4-8}$ or cardiovascular ${ }^{9-13}$ effects of very short-term exposures (typically $2 \mathrm{~h}$ or less) to traffic-related air pollution (TRAP) and diesel emissions in real-world settings. All are characterised by their quasi-experimental study design in which participants were taken to locations (busy traffic, inner city with diesel only, quiet park like) or underwent realistic commutes (in buses, cars or bicycling) where the investigators expected elevated exposures or contrasts in exposures to TRAP to occur. However, these designs have not yet been applied to the assessment of new point sources, such as emissions from road tunnels and their ventilation stacks.

A proposal to build a new road tunnel in Sydney with emissions vented to the surface via ventilation stacks presented us with an opportunity to prospectively test the hypothesis that short-term exposure to emissions from the tunnel ventilation stacks has an adverse effect on respiratory health.

\section{METHODS}

The study was conducted in Sydney, Australia between 2006 and 2008, and approved by the University of
Sydney Human Research Ethics Committee (HREC) on 17 August 2006.

\section{Study design and subjects}

The study was a randomised, controlled cross-over trial. Thirty-six volunteers were recruited through a university, student and workplace networks, and the Woolcock Institute of Medical Research's (WIMR) Volunteer Database. Eligibility criteria included nonsmokers, ability to walk easily for $2 \mathrm{~h}$, able to participate in 2006 and 2007 , sense of smell not compromised and not pregnant.

Study participants were randomised into three equalsize groups, which defined the order of exposure in the cross-over study. Three exposure conditions were tested: 'downwind' of the LCT western ventilation stack (putative adverse exposure), 'upwind' of the stack (negative control) and a 'heavily trafficked site' (positive control). The three exposures took place over 6 days in OctoberNovember in 2006, before the tunnel opened, and during the same months in 2007 and 2008, after the tunnel opened, to account for seasonal influences. Data collection extended to 2008, the second follow-up year, as it was expected that traffic volumes in the tunnel would be increased between 2007 and 2008. Traffic volumes in

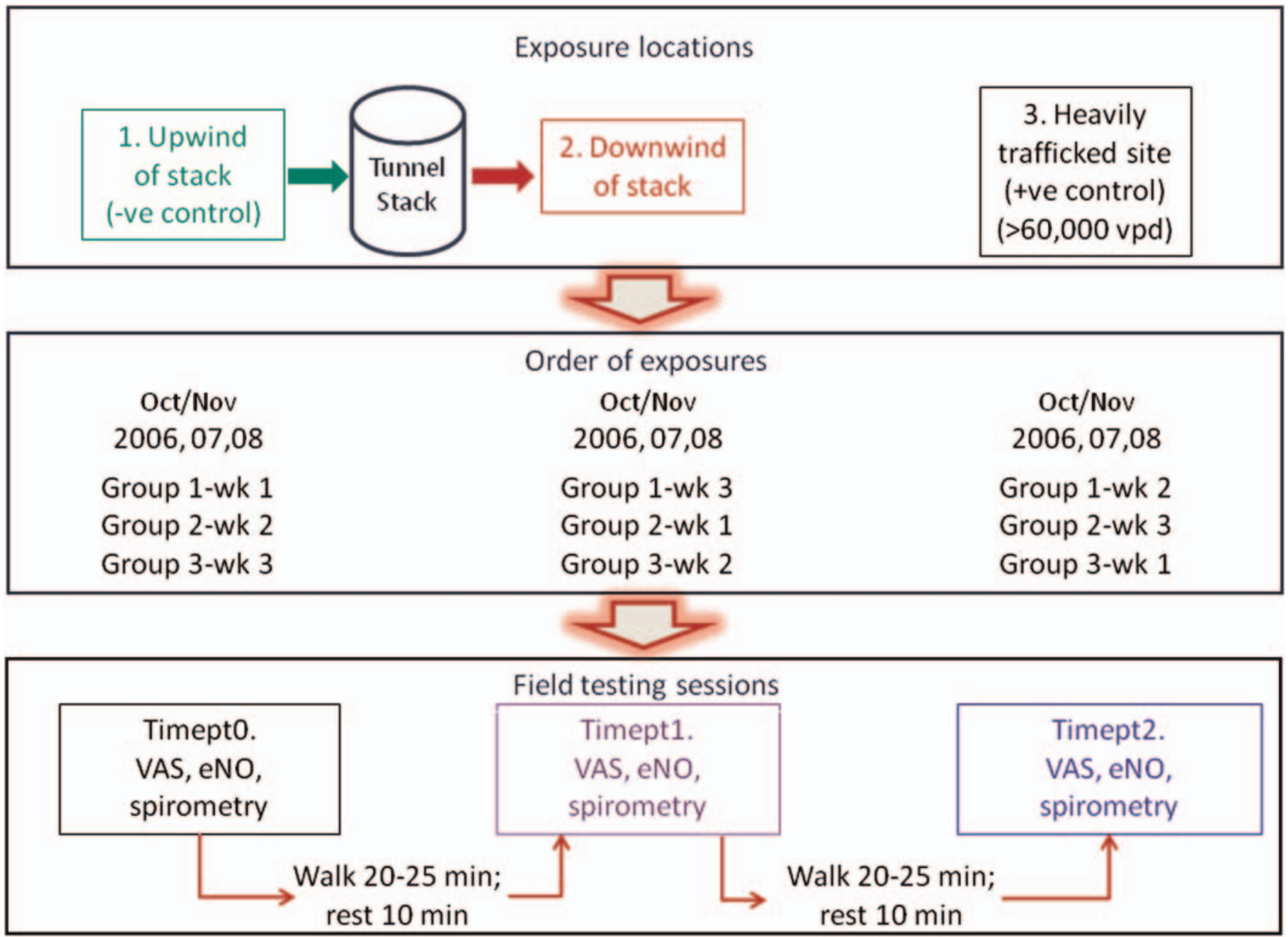

Figure 1 Schematic of fieldwork. 
November 2007 and 2008 were 49218 vehicles per day (vpd) and 58218 vpd respectively. Each exposure comprised two morning sessions during peak traffic periods (07:00-09:00) on two consecutive weekdays (Tuesdays and Wednesdays) (figure 1). There was a 6 day washout period between exposure conditions. The order of group allocation to exposure type was the same each year, except in 2008 where order of testing for two groups was changed twice due to changing wind conditions.

\section{Exposure locations}

The tunnel ventilation stacks are located at its eastern and western ends, respectively. As the eastern stack is located close to tunnel feeder roads, attribution of an effect solely due to the stack would be difficult. Hence, we decided to conduct the study at sites located around the western ventilation stack using predetermined walking routes (figure 2). The heavily trafficked (positive control) site was located alongside a major urban commuter road close to Sydney's central business district and remote from the study area. The annual average daily traffic volume at this site was 64418 vehicles per day during $2005 .^{14}$

We selected six sites in a 500-1000 m circumference around the stack and two sites on either side of the major commuter road. The stack sites were chosen based on the feasibility of accommodating testing procedures and identification of 20 min walking routes, which were all on quiet residential streets with low traffic volumes, and were not undulating. Participants were asked to walk at a comfortable, even pace.

For each study day, two of the six stack sites were selected and defined as 'upwind' or 'downwind' sites based on the wind direction recorded at 06:00 that morning.
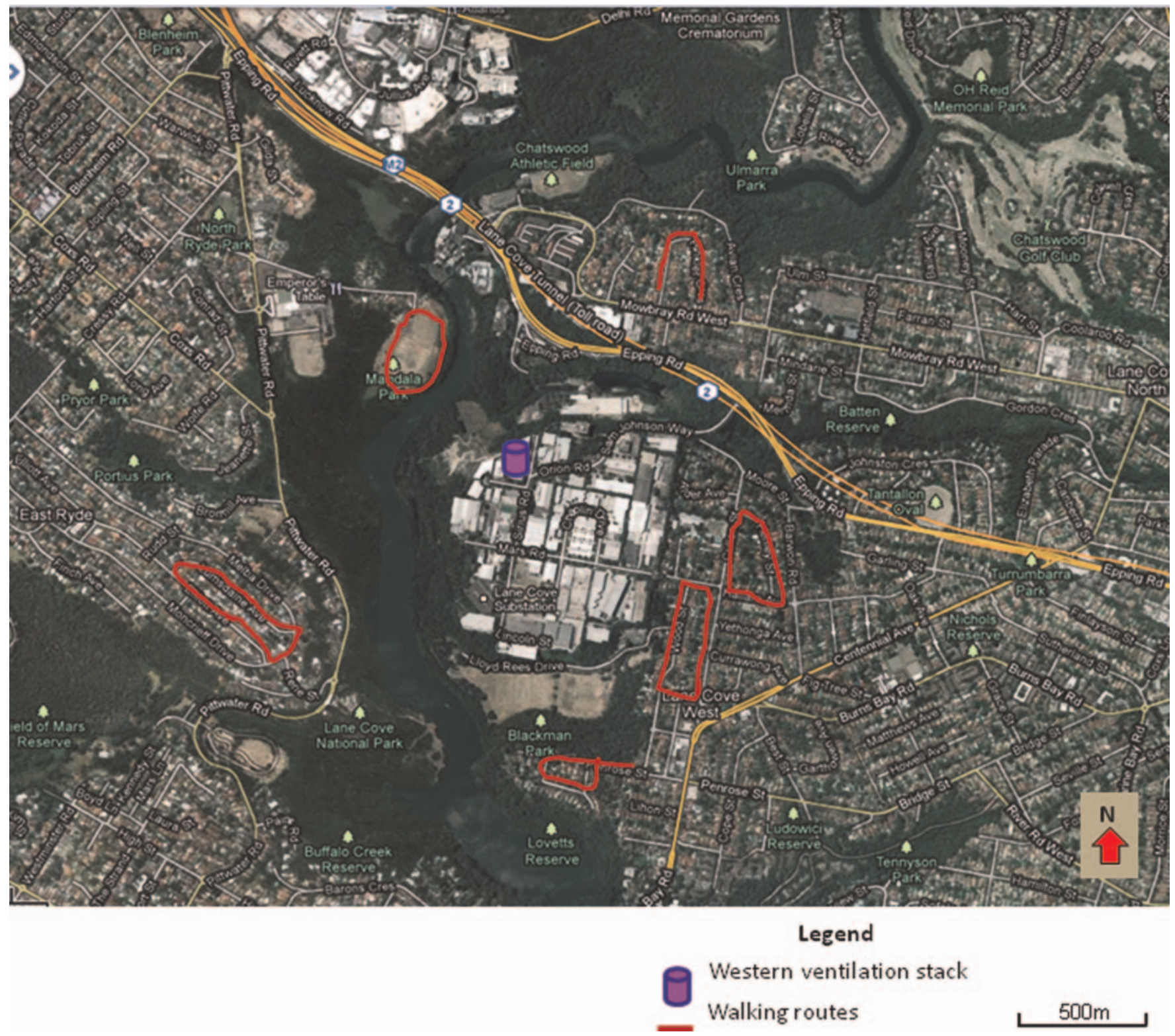

Figure 2 Study area and field sites. 


\section{Baseline assessment}

Prior to fieldwork we conducted spirometry, measured nitric oxide concentration in exhaled breath (eNO) and performed allergen skin prick tests (SPTs) on participants in the WIMR laboratory. Participants completed a questionnaire recording asthma diagnosis, wheeze, medication use, respiratory symptoms and odour perception, ${ }^{15-17}$ as experienced in the preceding 3 months. Participants also completed a series of 14 visual analogue scales (VAS) to rate their perception of respiratory and chest, nose, throat and eye symptoms. They rated odour perception (strength and annoyance) on a VAS if they responded affirmatively to detecting odour. Symptoms were ranked on VAS scales from 'no symptoms' $(0)$ to 'the worst I can imagine' (100). These data were used to determine pre-existing disease and to characterise the study population.

\section{Fieldwork}

Participants were either transported in a mini-van or made their own way to the field site. They were asked to wear N95 mask (Alpha Protech N95 particulate face mask certified to NIOSH standards) from when they left home each morning until measurements were made, to minimise exposure on route. They were asked to withhold long-acting bronchodilators for $12 \mathrm{~h}$ and shortacting bronchodilators for $6 \mathrm{~h}$ before fieldwork.

Each exposure period was started at 07:00 and lasted approximately $2 \mathrm{~h}$, incorporating two $20 \mathrm{~min}$ periods of walking and two rest periods (figure 1). During each exposure, subjects underwent three rounds of testing including completion of VAS forms, eNO measurement and spirometry, in that order, and at timepoints as indicated in figure 1. Participants were allocated to pairs for testing and walking, with each pairing maintained (as much as possible) throughout the 3 years of testing.

\section{Clinical tests}

We used a hand-held spirometer (QRS Diagnostic: Z-5000-2668) linked to Office Medic software (V. 4.5i) to record forced expiratory volume in $1 \mathrm{~s}\left(\mathrm{FEV}_{1}\right)$ and forced vital capacity (FVC). Spirometry was performed according to the American Thoracic Society/European Respiratory Society (ATS/ERS) criteria with technically unsatisfactory curves identified at the time of testing and again after fieldwork. These technically unsatisfactory curves were excluded from analysis. To improve reliability of the measures we chose the highest of two values reproducible within $150 \mathrm{ml}$ for $\mathrm{FEV}_{1}$ and $\mathrm{FVC}$. Where not reproducible, curves were rechecked for quality and, if acceptable, the highest measures for $\mathrm{FEV}_{1}$ and $\mathrm{FVC}$ were selected.

We used an off-line technique to measure eNO, according to ATS/ERS criteria $^{18}$ at an expiratory flow rate of $200 \mathrm{ml} / \mathrm{s}^{19}$ Exhaled breath was collected into a 3-litre chemically inert bag through a rotameter incorporating a filter and an NO scrubber on the inlet valve, to exclude the influence of ambient NO levels on personal
NO concentrations. The NO concentration was measured within $24 \mathrm{~h}$ of collection using a chemiluminescence analyser (ThermoEnvironmental $42^{\circ} \mathrm{C}$ ).

SPTs were performed using airborne allergens for house dust mites (Dermatophagoides pteronyssinus, D. farinae), mould (Alternaria, Aspergillus), cat pelt, dog, cockroach, ryegrass and grass mix (Hollister-Stier). ${ }^{20}$ Wheal sizes were measured as the average of the largest diameter and its perpendicular at $15 \mathrm{~min}$. Wheals larger than $3 \mathrm{~mm}$ in diameter and larger than the negative control were considered positive. Subjects with any positive SPT were classified as atopic.

\section{Air quality monitoring}

Air quality monitoring took place on each field testing day at each visited site, constituting a total of 18 measurement days. We collected samples for particulate matter $\left(\mathrm{PM}_{10}, \mathrm{PM}_{2.5}\right.$ and $\left.\mathrm{PM}_{1}\right)$, volatile organic compounds (VOCSs), total oxides of nitrogen (NOx), nitrogen dioxide $\left(\mathrm{NO}_{2}\right)$ and nitrogen oxide $(\mathrm{NO})$.

We used Osiris instruments to collect PM data in 2006 and 2007 and Topas units for collection of PM data in 2008 due to the unavailability of Osiris instruments. Concentrations of PM data were recorded as $2 \mathrm{~min}$ averages.

VOC samples were collected using a stainless-steel canister and inlet designed to collect an evenly spaced sample over the $2 \mathrm{~h}$ of fieldwork, providing an average reading. The samples were analysed at the CSIRO Laboratory in 2006 and 2008 for 1,3-butadiene, benzene, toluene, ethylbenzene, $m-+p$-xylene, $o$-xylene. Samples were analysed by an alternative laboratory in 2007 but the limit of detection (DL) was higher and given that many of the readings were below this DL we excluded the 2007 data.

Samples for ambient $\mathrm{NOx} / \mathrm{NO}_{2}$ were collected via grab samples every $15 \mathrm{~min}$ at each site using identical collection bags as those used for eNO collection. These were analysed (within $24 \mathrm{~h}$ ) as for eNO analysis.

We obtained continuously recorded data for 2006-2007 for $\mathrm{NO}_{2}, \mathrm{PM}_{10}$ and $\mathrm{PM}_{2.5}$ from two air quality monitors sited in elevated positions near the ventilation stacks and established by the tunnel proponents for statutory purposes. $^{21}$

\section{Wind direction}

Wind direction for each field day was determined using meteorological forecasts from the Bureau of Meteorology and by releasing slightly buoyant balloons filled with a mixture of air and helium from an elevated location near the western stack.

To validate our choice of testing sites, wind speed and direction data were obtained from three air quality monitoring stations located near the western ventilation stack, including the elevated site mentioned above. The other two were ground-level stations, operated for all three study years. We constructed wind roses for the three monitoring sites using Lakes Environmental WRPlot View (V.6.5.1). 
Post hoc validation of assignment of downwind and upwind study sites for each testing day was checked using wind rose data. Where the chosen locations were within $\pm 45^{\circ}$ of the measured downwind or upwind direction, they were deemed to be accurate downwind or upwind locations, respectively. This validation was used in the sensitivity analysis. Data for the heavily trafficked site (north or south side of the road) were included in the sensitivity analysis in the same way. Data were also excluded where wind speed was $<1 \mathrm{~m} / \mathrm{s}$.

\section{Analysis}

Health outcomes

The distributions of eNO were skewed and so these values were log-transformed. All other dependent variables were analysed without transformation.

Principal components analysis (PCA) was conducted to reduce the 14 symptom scores to five factors which were found to explain $77 \%$ of the overall variance. The scree plot suggested that this was the optimum number of factors. Hence, a five-factor structure was fitted with varimax rotation using data for all 3 years. The five-factor scores were output for each observation and these were used as continuous measures of symptom intensity. The five symptom factors were (1) itchy/dry/sore eyes and blocked nose (EYE); (2) sore/dry throat, sore chest and runny nose (THROAT); (3) chest tightness, difficulty breathing (CHEST); (4) sneezing, cough, watery eyes; (SNEEZE) and (5) dry-nose symptoms (DRY NOSE). The distributions of VAS scores for 'strong smell' and 'annoying smell' were highly skewed and included a large proportion of zero values, and so were treated as binary outcomes: zero ('no') and greater than zero ('yes').

To estimate the air pollutant means we first calculated the daily means for each pollutant, and then calculated the mean pollutant level by location and year.

We analysed the data using an 'intention to treat' approach, based on the locations chosen for each group for each field-testing session. Data for timepoint_0 were excluded from the main analyses based on the assumption that exposure had not started when that measurement was made. We used a mixed effects linear regression model in which the fixed effects were location (upwind, downwind, control) and year (2006, 2007, 2008), and used contrast statements to test specific interactions between them. We also used contrast statements to estimate the overall difference (averaged over all years) in effect between the heavily trafficked location and the upwind and downwind locations combined. Since we expected that health outcomes would be worse at the heavily trafficked site, this served as a validation of the design. We included a random intercept term for subjects, with a variance components covariance structure, to account for repeated measures within subjects. Spirometric outcomes, eNO and the five symptom factors were separately included as outcome variables. Significance of the fixed effects was tested using F tests. Least squares means were estimated for each combination of year and location. Analyses were conducted using SAS V.9.2 PROC MIXED procedures.

The binary variables 'strong smell' and 'annoying smell' were treated identically except that a generalised linear mixed model was fitted with Proc GLIMMIX using the adaptive quadrature estimation method, a logistic link and a binomial error distribution in SAS V.9.2. Examination of the distribution of residuals indicated that there were no major departures from normality and transformation of the data was not required.

\section{Air pollutant concentrations}

We used a similar mixed effects linear regression model with contrast statements, to test the effects of location and year, and their interaction, on air pollutant measurements (NOx, $\mathrm{NO}_{2}, \mathrm{PM}_{10}, \mathrm{PM}_{2.5}$ and $\mathrm{PM}_{1}$ ), excluding VOCs where there were too few readings. A random intercept term for days was used to account for repeated measures. We conducted a sensitivity analysis for the air quality data by re-fitting the models using data that were validated using the wind-rose method, as described earlier.

For the elevated monitor data, we used an autoregressive error model with Yule-Walker estimates and stepwise regression to determine whether there was a difference in air quality between 2006 (pretunnel) and 2007 (posttunnel opening), by comparing daily averages for the 2 years. We adjusted this analysis for changes in regional air quality measured at three regulatory monitoring stations operated by the Department of Environment, Climate Change and Water (DECCW), including as a covariate the change in average daily readings from the DECCW sites combined. We tested up to 20 lags, residuals were plotted to check for normality, and the autocorrelation function and partial autocorrelation function were checked for autocorrelation. These models were implemented in SAS 9.2 using the AUTOREG procedure.

\section{Sample size and power calculation}

The sample size for this study (36 subjects) was selected by reference to a study conducted in London that was able to detect significant within-subject differences in lung function in 60 subjects exposed to a high pollution area and a low pollution area, ${ }^{5}$ noting that our study had a greater number of repeated measures.

\section{RESULTS}

In 2006, 25\% of the 36 participants reported having had a diagnosis of asthma and $42 \%$ reported having had wheeze, including $25 \%$ who had wheeze in the last 3 months (table 1). The majority of participants were atopic. Of the 36 subjects who started the study in 2006 , $26(72 \%)$ participated in 2007 and $20(56 \%)$ in 2008. While the cohort characteristics remained relatively stable between 2006 and 2007, in 2008 the remaining cohort was less symptomatic in the 3 months prior to 2008 field testing (table 1, supplementary material). 


\begin{tabular}{|c|c|}
\hline Symptom/characteristic & $\mathbf{N}(\%)$ \\
\hline Total number of subjects & $36(100)$ \\
\hline Asthma (ever diagnosis) & $9(25)$ \\
\hline Ever wheezed & $15(42)$ \\
\hline Wheeze (in last 3 months) & $9(25)$ \\
\hline Breathless (in last 3 months) & $4(11)$ \\
\hline Cough (in last 3 months) & $20(56)$ \\
\hline Activities limited (in last 3 months) & $3(8)$ \\
\hline Ever taken asthma medication & $15(42)$ \\
\hline Asthma medication (in last 3 months) & $8(22)$ \\
\hline Inhaled steroids (in last 3 months)* & $6(17)$ \\
\hline Sensitive eyes† & $12(33)$ \\
\hline $\begin{array}{l}\text { Eye symptoms (in the last } 3 \text { months without } \\
\text { a cold/flu) } \ddagger\end{array}$ & $14(39)$ \\
\hline $\begin{array}{l}\text { Nose symptoms (in the last } 3 \text { months } \\
\text { without a cold/flu) }\end{array}$ & $18(50)$ \\
\hline $\begin{array}{l}\text { Throat symptoms (in the last } 3 \text { months } \\
\text { without a cold/flu) }\end{array}$ & $10(28)$ \\
\hline $\begin{array}{l}\text { Mouth symptoms (in the last } 3 \text { months } \\
\text { (soreness of gums or teeth)) }\end{array}$ & $13(36)$ \\
\hline Atopic§ & $26(72)$ \\
\hline Female & $25(69)$ \\
\hline Spirometry and chemical sensitivity score & Mean (SD) \\
\hline $\mathrm{FEV}_{1}(\mathrm{~L})$ & $2.99(0.94)$ \\
\hline FVC (L) & $3.78(1.11)$ \\
\hline eNO $(\mathrm{ppb})$ & $11.1(12.1)$ \\
\hline Chemical sensitivity scale score (CSS) ${ }^{17}$ & $36.3(8.7)$ \\
\hline \multicolumn{2}{|c|}{$\begin{array}{l}\text { *Inhaled steroids=having taken either seretide or pulmicort. } \\
\text { tQuestion: Do you usually regard your eyes as being sensitive to } \\
\text { cigarette smoke, smog, air conditioning or central heating? } \\
\text { fQuestion: Have you had any of the following eye symptoms in } \\
\text { the last } 3 \text { months, when you did not have a cold or flu (eye } \\
\text { redness, burning feeling, scratchiness, grittiness, dryness or } \\
\text { watery eyes)? } \\
\text { §Any allergen SPT } \geq 3 \mathrm{~mm} \text {. }\end{array}$} \\
\hline
\end{tabular}

\section{Health outcomes}

$\mathrm{FEV}_{1}$ and FVC were similar across locations, but were generally higher in 2006 compared to 2007 or 2008 (table 2). Mean values for eNO were highest at the heavily trafficked (positive control) location for all years except for 2008 and did not differ between the downwind and upwind locations. EYE, THROAT and CHEST symptom scores were highest at the heavily trafficked location compared to the downwind or upwind locations during all years, with one exception (table 2).

There was little evidence that the downwind locations, when compared with the heavily trafficked or upwind locations, were associated with adverse health outcomes in 2007 or 2008, compared to 2006 (table 3). The only exception was that changes in DRY NOSE scores were higher for downwind versus heavily trafficked locations. Downwind locations were associated with a decrease in reporting of chest symptoms for almost all year comparisons.

Over the 3-year period as a whole, exposure at the heavily trafficked locations, compared with both the downwind and upwind stack locations, was associated with more airway inflammation $(\mathrm{eNO})(\mathrm{ratio}=1.09)$, and

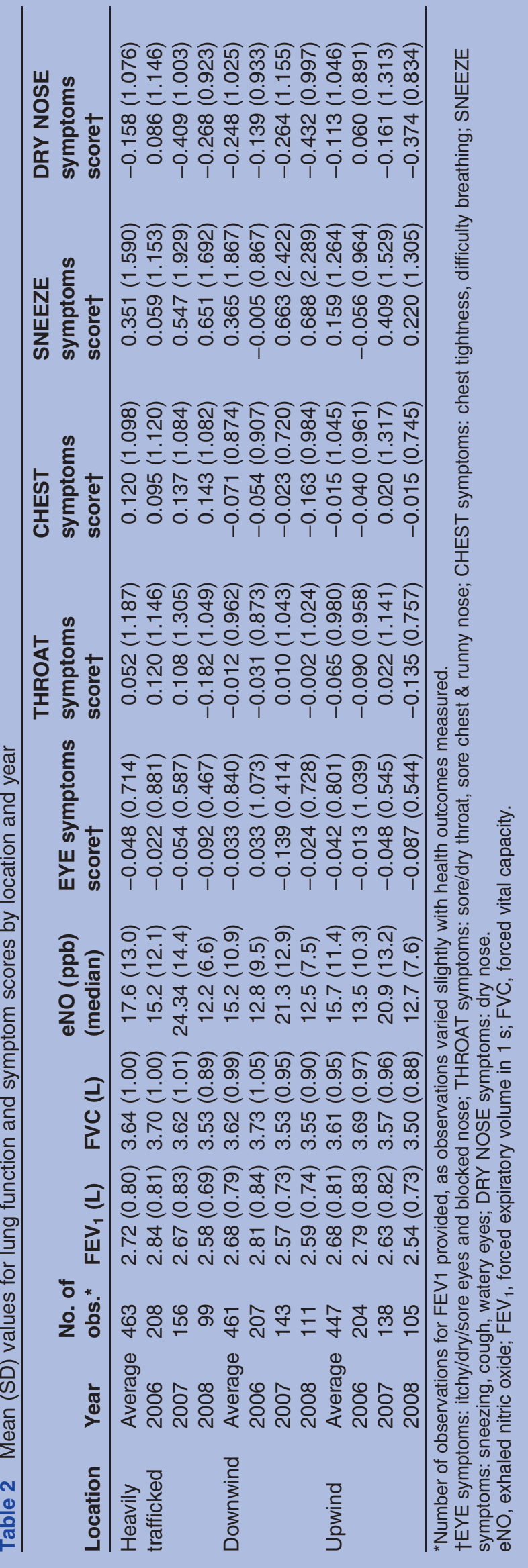


Table 3 Contrasts* in lung function, eNO and symptom scores between the downwind site and the other two sites (upwind and heavily trafficked) adjusted for change from baseline (2006) to subsequent years

\begin{tabular}{|c|c|c|c|c|c|c|}
\hline \multicolumn{2}{|l|}{ Contrast $^{\star}$} & \multirow{2}{*}{$\begin{array}{l}\text { FEV1 (diff in litres) } \\
(95 \% \mathrm{Cl})\end{array}$} & \multirow{2}{*}{$\begin{array}{l}\text { FVC (diff in litres) } \\
(95 \% \mathrm{Cl})\end{array}$} & \multirow[b]{2}{*}{ eNO ratio $(95 \% \mathrm{Cl})$} & \multirow{2}{*}{$\begin{array}{l}\text { EYE symptoms } \\
\text { (diff in score) }(95 \% \mathrm{Cl})\end{array}$} & \multirow{2}{*}{$\begin{array}{l}\text { THROAT symptoms } \\
\text { (diff in score) }(95 \% \mathrm{Cl})\end{array}$} \\
\hline Location & Year & & & & & \\
\hline \multirow{3}{*}{$\begin{array}{l}\text { Downwind versus } \\
\text { (heavily trafficked and } \\
\text { upwind) } \dagger\end{array}$} & $2007 / 2008$ vs $2006 \ddagger$ & $0.01(-0.04$ to 0.06$)$ & $0.03(-0.03$ to 0.09$)$ & 1.03 (0.94 to 1.12$)$ & $\begin{array}{l}-0.006 \\
(-0.097 \text { to } 0.086)\end{array}$ & $0.130(-0.084-0.344)$ \\
\hline & 2007 vs 2006 & $0.03(-0.03$ to 0.09$)$ & $0.05(-0.03$ to 0.13$)$ & $1.01(0.91$ to 1.11$)$ & $\begin{array}{l}-0.055 \\
(-0.159 \text { to } 0.049)\end{array}$ & $0.041(-0.220-0.301)$ \\
\hline & 2008 vs 2006 & $-0.004(-0.07$ to 0.06$)$ & $0.02(-0.07$ to 0.10$)$ & 1.05 (0.94 to 1.17$)$ & $0.043(-0.074$ to 0.159$)$ & $0.207(-0.027$ to 0.441$)$ \\
\hline \multirow[t]{3}{*}{$\begin{array}{l}\text { Downwind versus } \\
\text { upwind }\end{array}$} & $2007 / 2008$ vs $2006^{\ddagger}$ & $0.02(-0.04$ to 0.08$)$ & $0.06(-0.02$ to 0.13$)$ & 1.03 (0.93 to 1.14$)$ & $\begin{array}{l}-0.044 \\
(-0.151 \text { to } 0.063)\end{array}$ & $0.080(-0.169$ to 0.329$)$ \\
\hline & 2007 vs 2006 & $0.04(-0.03$ to 0.11$)$ & $0.06(-0.03$ to 0.15$)$ & $1.05(0.94$ to 1.17$)$ & $\begin{array}{l}-0.108 \\
(-0.229 \text { to } 0.012)\end{array}$ & $-0.006(-0.308$ to 0.297$)$ \\
\hline & 2008 vs 2006 & $0.004(-0.07$ to 0.08$)$ & $0.06(-0.04$ to 0.15$)$ & 1.01 (0.89 to 1.15$)$ & $0.015(-0.120$ to 0.149$)$ & $0.179(-0.092$ to 0.449$)$ \\
\hline Downwind versus & $2007 / 2008$ vs $2006 \ddagger$ & $-0.00(-0.06$ to 0.06$)$ & 0.004 ( -0.07 to 0.08$)$ & $1.03(0.93$ to 1.14$)$ & $0.033(-0.073$ to 0.140$)$ & $0.180(-0.068$ to 0.428$)$ \\
\hline \multirow[t]{2}{*}{ heavily trafficked } & 2007 vs 2006 & $0.02(-0.05$ to 0.09$)$ & 0.04 (-0.05 to 0.12$)$ & 0.97 (0.87 to 1.08$)$ & $\begin{array}{l}-0.002 \\
(-0.121 \text { to } 0.117)\end{array}$ & $0.087(-0.212$ to 0.385$)$ \\
\hline & 2008 vs 2006 & $-0.01(-0.09$ to 0.06$)$ & $-0.03(-0.12$ to 0.07$)$ & 1.09 (0.96 to 1.23$)$ & $0.071(-0.065$ to 0.206$)$ & $0.236(-0.038$ to 0.509$)$ \\
\hline $\begin{array}{l}\text { Heavily trafficked } \\
\text { versus (upwind and } \\
\text { downwind)§ }\end{array}$ & Overall & $-0.01(-0.04$ to 0.01$)$ & $-0.03(-0.06$ to 0.002$)$ & 1.09 (1.04 to 1.14$)$ & 0.054 (0.006 to 0.102$)$ & $0.107(-0.005$ to 0.218$)$ \\
\hline \multirow{3}{*}{$\begin{array}{l}\text { Downwind versus } \\
\text { (heavily trafficked and } \\
\text { upwind) } \dagger\end{array}$} & $2007 / 2008$ vs $2006 \ddagger$ & $\begin{array}{l}-0.080 \\
(-0.302 \text { to } 0.142)\end{array}$ & $\begin{array}{l}0.288 \\
(-0.139 \text { to } 0.716)\end{array}$ & $0.276(0.040$ to 0.511$)$ & 3.45 (1.57 to 7.60$)$ & $1.69(0.72$ to 3.96$)$ \\
\hline & 2007 vs 2006 & $\begin{array}{l}-0.031 \\
(-0.277 \text { to } 0.214)\end{array}$ & $\begin{array}{l}0.375 \\
(-0.093 \text { to } 0.844)\end{array}$ & $0.320(0.053-0.587)$ & 5.72 (2.35 to 13.91$)$ & 1.95 (0.77 to 4.94$)$ \\
\hline & 2008 vs 2006 & $\begin{array}{l}-0.133 \\
(-0.409 \text { to } 0.143)\end{array}$ & $\begin{array}{l}0.182 \\
(-0.254 \text { to } 0.618)\end{array}$ & $\begin{array}{l}0.229 \\
(-0.057 \text { to } 0.516)\end{array}$ & 2.14 (0.77 to 5.97$)$ & $1.33(0.44$ to 4.00$)$ \\
\hline \multirow[t]{3}{*}{$\begin{array}{l}\text { Downwind versus } \\
\text { upwind }\end{array}$} & $2007 / 2008$ vs $2006 \ddagger$ & $\begin{array}{l}-0.017 \\
(-0.275 \text { to } 0.242)\end{array}$ & $\begin{array}{l}0.430 \\
(-0.067 \text { to } 0.927)\end{array}$ & $\begin{array}{l}0.193 \\
(-0.081 \text { to } 0.466)\end{array}$ & $3.51(1.40$ to 8.80$)$ & $1.23(0.45$ to 3.40$)$ \\
\hline & 2007 vs 2006 & $\begin{array}{l}0.033 \\
(-0.252 \text { to } 0.318)\end{array}$ & $\begin{array}{l}0.422 \\
(-0.123 \text { to } 0.966)\end{array}$ & $\begin{array}{l}0.187 \\
(-0.124 \text { to } 0.498)\end{array}$ & 4.11 (1.48 to 11.43$)$ & $1.12(0.38$ to 3.37$)$ \\
\hline & 2008 vs 2006 & $\begin{array}{l}-0.042 \\
(-0.362 \text { to } 0.277)\end{array}$ & $\begin{array}{l}0.424 \\
(-0.080 \text { to } 0.929)\end{array}$ & $\begin{array}{l}0.178 \\
(-0.154 \text { to } 0.510)\end{array}$ & 3.31 (0.98 to 11.18$)$ & $1.26(0.34$ to 4.71$)$ \\
\hline \multirow[t]{3}{*}{$\begin{array}{l}\text { Downwind versus } \\
\text { heavily trafficked }\end{array}$} & $2007 / 2008$ vs $2006 \ddagger$ & $\begin{array}{l}-0.143 \\
(-0.400 \text { to } 0.114)\end{array}$ & $\begin{array}{l}0.147 \\
(-0.349 \text { to } 0.642)\end{array}$ & $0.358(0.086$ to 0.631$)$ & 3.39 (1.39 to 8.29$)$ & 2.31 (0.90 to 5.94$)$ \\
\hline & 2007 vs 2006 & $\begin{array}{l}-0.096 \\
(-0.377 \text { to } 0.185)\end{array}$ & $\begin{array}{l}0.329 \\
(-0.208 \text { to } 0.866)\end{array}$ & $0.453(0.146$ to 0.759$)$ & 7.96 (2.89 to 21.93$)$ & 3.38 (1.20 to 9.54$)$ \\
\hline & 2008 vs 2006 & $\begin{array}{l}-0.224 \\
(-0.547 \text { to } 0.099)\end{array}$ & $\begin{array}{l}-0.060 \\
(-0.570-0.450)\end{array}$ & $\begin{array}{l}0.281 \\
(-0.054 \text { to } 0.617)\end{array}$ & $1.38(0.44$ to 4.40$)$ & $1.40(0.41$ to 4.75$)$ \\
\hline $\begin{array}{l}\text { Heavily trafficked } \\
\text { versus (upwind and } \\
\text { downwind)§ }\end{array}$ & Overall & $\begin{array}{l}0.209 \\
(0.094 \text { to } 0.325)\end{array}$ & $\begin{array}{l}0.150 \\
(-0.072 \text { to } 0.372)\end{array}$ & $0.022(-0.101$ to 0.144$)$ & 2.34 (1.58 to 3.49$)$ & 4.08 (2.67 to 6.25$)$ \\
\hline
\end{tabular}

${ }^{*}$ Contrasts are derived from mixed effects regression model in which location and year, and the interaction between them are fixed effects, and individual subject intercepts are a random effect. Main contrasts of interest are those included in the table and consist of downwind versus other exposures, as the downwind exposure is the primary exposure of interest in this study. †Downwind versus (heavily trafficked and upwind) is the comparison of downwind versus heavily trafficked and upwind exposures combined.

$\$ 2007 / 2008$ vs 2006 represents the comparison of both post-tunnel years combined (2007/2008) versus the pre-tunnel year (2006)

$\S$ Represents the overall comparison of the heavily trafficked site compared to the upwind and downwind sites combined (data from all years included), as we anticipated the heavily trafficked site to have higher air pollution levels and that health effects would be more prominent.

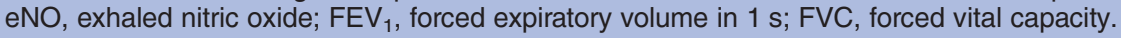


higher scores for EYE, CHEST and THROAT symptoms (last row, table 3). These findings support the validity of the study design and analysis.

The change in 'smell_strong' from 2006 to subsequent years was higher for downwind locations than the other two locations (table 3). However, in general this pattern was not observed for 'smell-annoying'. Overall, both 'smell-strong' and 'smell-annoying' were higher at the heavily trafficked locations than the two stack locations (last row, table 3).

Sensitivity analysis for health outcomes

In the sensitivity analysis we excluded data that might have led to exposure misclassification due to unexpected wind direction, as described earlier. Data for five 'downwind' sites in 2006 and two in 2008, for two 'upwind' sites in 2006 and two in 2008, and for one heavily trafficked site in 2006 were excluded.

In this analysis FVC was increased for downwind locations versus the other two locations, for most year comparisons (table 2, supplementary material). $\mathrm{FEV}_{1}$ was also increased for downwind versus heavily trafficked locations. Conversely, eNO was higher at downwind compared to upwind locations for 2007 vs 2006. The increased odds of 'smell-strong' at downwind locations did not differ to the other locations in the sensitivity analysis. Overall, eNO levels, CHEST symptoms, 'smell-strong' and 'smell-annoying' were higher at the heavily trafficked

Table 4 Mean pollutant levels by location (2006-2008 overall)

\begin{tabular}{|c|c|c|c|c|c|c|c|c|}
\hline Pollutant & Location & Sample days & Samples & Mean* & Median* & IQR & Min & Max \\
\hline \multicolumn{9}{|c|}{ Nitrogen oxides } \\
\hline \multirow[t]{3}{*}{ NOx } & Heavily trafficked & 18 & 157 & 126.2 & 95.2 & $28.1-133.1$ & 7.9 & 650.7 \\
\hline & Downwind & 18 & 159 & 23.9 & 16.2 & $8.0-38.5$ & 3.5 & 66.3 \\
\hline & Upwind & 18 & 150 & 26.2 & 15.8 & $8.6-32.8$ & 3.6 & 84.4 \\
\hline \multirow[t]{3}{*}{$\mathrm{NO}_{2}$} & Heavily trafficked & 18 & 160 & 6.1 & 3.8 & $1.2-5.7$ & -2.3 & 27.8 \\
\hline & Downwind & 18 & 159 & 3.1 & 2.3 & $1.2-4.2$ & 0.8 & 9.4 \\
\hline & Upwind & 18 & 151 & 3.1 & 1.8 & $1.4-4.5$ & 0.6 & 10.4 \\
\hline \multicolumn{9}{|c|}{ Particulate matter $¥$} \\
\hline \multirow[t]{3}{*}{$\mathrm{PM}_{10}$} & Heavily trafficked & 17 & 1034 & 52.6 & 45.1 & $35.4-64.2$ & 28.3 & 108.5 \\
\hline & Downwind & 17 & 1099 & 41.9 & 33.5 & $29.7-49.9$ & 17.1 & 90.4 \\
\hline & Upwind & 17 & 1087 & 45.9 & 35.2 & $25.4-49.5$ & 16.7 & 132.8 \\
\hline \multirow[t]{3}{*}{$\mathrm{PM}_{2.5}$} & Heavily trafficked & 17 & 1034 & 13.0 & 13.9 & $9.6-16.5$ & 4.2 & 20.0 \\
\hline & Downwind & 17 & 1099 & 11.0 & 10.4 & $7.9-13.5$ & 1.5 & 19.7 \\
\hline & Upwind & 17 & 1087 & 11.7 & 10.6 & $9.2-13.4$ & 1.7 & 28.5 \\
\hline \multirow[t]{3}{*}{$\mathrm{PM}_{1}$} & Heavily trafficked & 17 & 1034 & 2.4 & 2.5 & $1.9-3.0$ & 1.1 & 3.4 \\
\hline & Downwind & 17 & 1099 & 1.9 & 1.9 & $1.5-2.3$ & 0.3 & 3.2 \\
\hline & Upwind & 17 & 1087 & 2.0 & 2.0 & $1.5-2.4$ & 0.5 & 5.1 \\
\hline \multicolumn{9}{|l|}{ VOCs§ } \\
\hline \multirow[t]{3}{*}{ Benzene } & Heavily trafficked & 12 & 12 & 0.86 & 0.86 & $0.44-1.07$ & 0.35 & 1.7 \\
\hline & Downwind & 12 & 12 & 0.39 & 0.37 & $0.18-0.55$ & 0.16 & 0.75 \\
\hline & Upwind & 12 & 12 & 0.37 & 0.27 & $0.23-0.49$ & 0.13 & 0.87 \\
\hline \multirow{3}{*}{ Butadiene } & Heavily trafficked & 12 & 12 & 0.25 & 0.25 & $0.11-0.33$ & 0.04 & 0.59 \\
\hline & Downwind & 12 & 12 & 0.11 & 0.11 & $0.04-0.18$ & 0.04 & 0.24 \\
\hline & Upwind & 12 & 12 & 0.11 & 0.09 & $0.07-0.16$ & 0.04 & 0.30 \\
\hline \multirow[t]{3}{*}{ Toluene } & Heavily trafficked & 10 & 10 & 5.25 & 4.60 & $2.60-6.80$ & 1.50 & 10.80 \\
\hline & Downwind & 10 & 10 & 2.61 & 2.55 & $2.20-3.00$ & 1.40 & 3.90 \\
\hline & Upwind & 10 & 10 & 3.58 & 3.55 & $2.30-4.00$ & 1.20 & 7.00 \\
\hline \multirow[t]{3}{*}{ Ethyl-benzene } & Heavily trafficked & 12 & 12 & 0.66 & 0.59 & $0.29-1.02$ & 0.15 & 1.70 \\
\hline & Downwind & 12 & 12 & 0.45 & 0.38 & $0.21-0.60$ & 0.09 & 1.50 \\
\hline & Upwind & 12 & 12 & 0.51 & 0.36 & $0.22-0.46$ & 0.09 & 1.90 \\
\hline \multirow[t]{3}{*}{ mp-xylene } & Heavily trafficked & 12 & 12 & 2.43 & 1.70 & $0.81-3.31$ & 0.55 & 7.70 \\
\hline & Downwind & 12 & 12 & 1.25 & 1.35 & $0.49-1.70$ & 0.28 & 2.80 \\
\hline & Upwind & 12 & 12 & 1.22 & 0.88 & $0.46-1.60$ & 0.30 & 4.00 \\
\hline \multirow[t]{3}{*}{ o-xylene } & Heavily trafficked & 12 & 12 & 0.90 & 0.70 & $0.34-1.23$ & 0.22 & 2.70 \\
\hline & Downwind & 12 & 12 & 0.50 & 0.52 & $0.19-0.77$ & 0.13 & 1.10 \\
\hline & Upwind & 12 & 12 & 0.49 & 0.37 & $0.21-0.64$ & 0.10 & 1.60 \\
\hline
\end{tabular}

*Means and medians calculated by taking the mean of daily averages at each site. IQR, minimum and maximum values using all (not averaged) data.

†Grab sample for $\mathrm{NO}_{2}$ and $\mathrm{NOx}$ collected at each site every $15 \mathrm{~min}$ and averaged per $2 \mathrm{~h}$ exposure period.

†PM data collected every 2 min.

§One sample collected at site providing an average VOC reading per $2 \mathrm{~h}$ exposure period. 2007 data not used in analysis due to different detection limits used by different laboratory. 95th percentile not reported for VOCs as sample size too small; 95th percentile equivalent to maximum reading.

PM, particulate matter; NOx, oxides of nitrogen. 
locations compared to upwind or downwind locations, confirming the findings of the intention-to-treat analysis (table 2, supplementary material).

\section{Air pollutant levels}

As expected, the concentrations of all pollutants were higher at the heavily trafficked sites than the upwind or downwind sites. However, there was little difference in mean pollutant levels between the downwind and upwind locations around the ventilation stack (tables 3 and 4, supplementary material). $\mathrm{NOx}$ and $\mathrm{NO}_{2}$ ratios were lower for the downwind sites than the other two sites for 2007 vs 2006. In contrast, the $\mathrm{NO}_{2}$ ratio for 2008 vs 2006 was higher at the downwind sites than at the heavily trafficked sites (table 5). The change in PM (for all size fractions) from 2006 to subsequent years did not vary by site. Overall, the change in pollutants was greatest at the heavily trafficked sites compared to the upwind and downwind sites combined.

In the sensitivity analysis the pollutant ratios for downwind locations compared to upwind locations increased for most pollutants supporting the validity of the exclusion criteria (table 4 , supplementary material).

$\mathrm{NO}_{2}$ and $\mathrm{PM}_{10}$ decreased at the western and eastern elevated monitoring sites between 2006 and 2007, after adjusting for changes in regional air quality (table 6).

\section{DISCUSSION}

We did not detect any consistent evidence of detrimental effects on lung function, airway inflammation or respiratory symptoms attributable to short-term exposure to emissions from the tunnel ventilation stack with the exception of increased reporting of dry nose symptoms. This absence of any adverse health effect might be explained by the fact that we did not measure higher pollutant concentrations at the downwind stack sites after the tunnel opened. The finding of increased pollutant levels and increased symptoms and airway inflammation during periods of exposure at the heavily trafficked site supports previous evidence of the detrimental effects of short-term exposures to TRAP.

This study relied on the proposition that the downwind sites we selected were, in fact, exposed to emissions from the tunnel ventilation stack during peak traffic periods. For a downwind site to be impacted by the emission plume from the stack the plume needed to be mixed at ground level prior to reaching the site and subjected to consistent wind direction during the sampling period. We used weather balloons early on each study morning in order to select the most appropriate downwind site. Compared to the upwind locations, pollutant concentrations at the downwind locations were similar, or sometimes slightly lower. This may have reflected actual conditions in the field suggesting that there was little measurable impact of the plume on the pollutants measured. However, this finding may have also arisen due to inaccurate prediction of the ground-level location of the

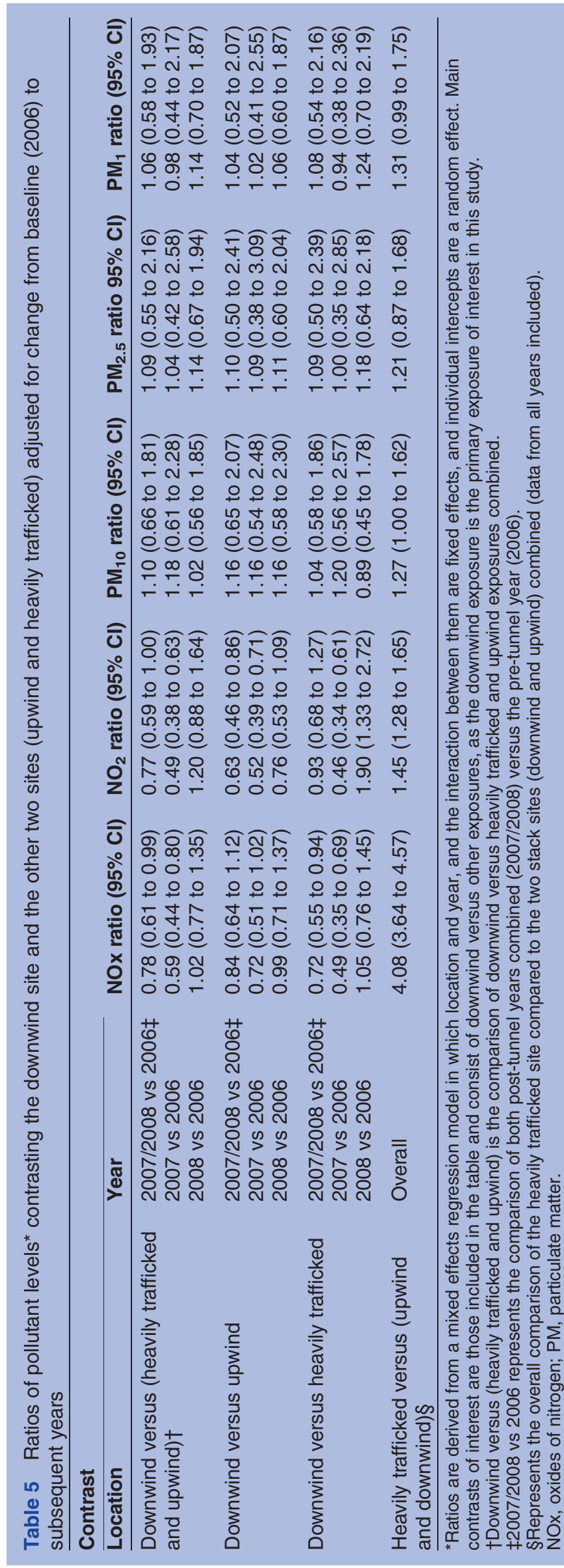


Table 6 Mean pollutant concentrations for elevated monitors by year and difference in pollutant concentration from post-tunnel year compared to pre-tunnel year

\begin{tabular}{|c|c|c|c|c|}
\hline \multirow[b]{2}{*}{ Site and pollutant } & \multicolumn{2}{|c|}{ Mean pollutant levels (SD) } & \multicolumn{2}{|c|}{ Difference in pollutant levels 2007 versus 2006* } \\
\hline & 2006 & 2007 & Unadjusted estimate (95\% Cl) & Adjusted estimate $(95 \% \mathrm{Cl}) \dagger$ \\
\hline \multicolumn{5}{|c|}{ Elevated site near western ventilation stack } \\
\hline $\mathrm{NO}_{2}(\mathrm{ppb})$ & $13.4(5.6)$ & $12.1(4.5)$ & $-1.93(-3.06,-0.80)$ & $-1.06(-1.67,-0.44)$ \\
\hline NOx $(\mathrm{ppb})$ & $26.1(19.9)$ & $20.6(14.6)$ & $-5.97(-11.20,-0.74)$ & $-2.74(-4.42$ to -1.06$)$ \\
\hline $\mathrm{PM}_{10}\left(\mu \mathrm{g} / \mathrm{m}^{3}\right)$ & $18.7(7.4)$ & $16.2(7.0)$ & $-2.40(-4.23,-0.57)$ & $-0.45(-1.95,1.04)$ \\
\hline $\mathrm{PM}_{2.5}\left(\mu \mathrm{g} / \mathrm{m}^{3}\right)$ & $6.2(3.5)$ & $5.3(3.3)$ & $-1.01(-2.27,0.25)$ & $-0.20(-0.66,0.27)$ \\
\hline \multicolumn{5}{|c|}{ Elevated site near eastern ventilation stack } \\
\hline $\mathrm{NO}_{2}(\mathrm{ppb})$ & $16.7(7.0)$ & $15.7(5.3)$ & $-2.50(-4.41,-0.60)$ & $-0.99(-2.21,0.23)$ \\
\hline NOx (ppb) & $30.7(17.8)$ & $27.1(14.1)$ & $-6.28(-10.93,-1.62)$ & $-2.05(-2.91,-1.20)$ \\
\hline $\mathrm{PM}_{10}\left(\mu \mathrm{g} / \mathrm{m}^{3}\right)$ & $20.2(8.1)$ & $16.1(6.8)$ & $-4.02(-6.24,-1.80)$ & $-1.75(-3.05,-0.44)$ \\
\hline $\mathrm{PM}_{2.5}\left(\mu \mathrm{g} / \mathrm{m}^{3}\right)$ & $6.4(3.6)$ & $5.3(3.2)$ & $-1.14(-2.40,0.11)$ & $-0.26(-0.65,0.12)$ \\
\hline
\end{tabular}

${ }^{*}$ Represents the change in pollutant concentration between pre-tunnel (25 March 2006-24 March 2007) and post-tunnel

(25 March 2007-24 March 2008).

†Adjusted for change in air quality at the three regional sites.

NOx, oxides of nitrogen; PM, particulate matter.

plume. Nevertheless, the sensitivity analysis we conducted was designed to address this potential weakness. The findings of that analysis support the original analysis.

Our finding that eNO, an indicator of airway inflammation, was increased at the heavily trafficked site is consistent with evidence of increased airway inflammation after exposure to TRAP (or diesel) in previous studies. These studies have varied in their measured end-points but include 'real-world' exposure studies investigating neutrophilic airway inflammation, ${ }^{45}$ associations between eNO and $\mathrm{PM}_{2.5}$, black carbon and fine particle counts ${ }^{6}$ and chamber studies reporting increased neutrophilic airway inflammation, ${ }^{22-25}$ increases in pro-inflammatory cytokines interleukin (IL)- $6^{26}$ and IL-8, ${ }^{25}$ increased exhaled carbon monoxide $(\mathrm{CO})^{22}$ and increased airway resistance. ${ }^{26} 27$

The absence of effects on spirometric function, even at the heavily trafficked site, is consistent with findings of chamber studies of diesel exhaust, ${ }^{22}{ }^{24-27}$ high particle concentrations, ${ }^{28}$ and $\mathrm{NO}_{2},{ }^{29}$ an in-tunnel study ${ }^{30}$ and a commuter study. ${ }^{8}$ However, our findings are inconsistent with the London study of diesel exhaust exposures which demonstrated small reductions in $\mathrm{FEV}_{1}$ after 1$2 \mathrm{~h}$ exposures. ${ }^{5}$

Strengths of the study include the randomised crossover design and blinding of participants by using upwind and downwind stack sites. It is unlikely that the participants were aware of the upwind/downwind status of their location on any given day. The study was further strengthened by including the heavily trafficked sites as a positive control. The finding that pollutant levels were higher, and that subjects had greater airway inflammation, eye and chest symptom scores at this site, support the validity of the study methodology. The before/after nature of our study and repeated measures within and across years also strengthened the study design.

A limitation of our study is the differential loss from the groups over time. Common reasons for nonparticipation in follow-up years were travel overseas, residence relocation and changing work practices, all factors unrelated to the experience of study participation.

In conclusion, while we found that this ventilation stack, under current operating conditions, had little measurable short-term health impact, we did demonstrate adverse health effects attributable to short-term exposures to TRAP at heavily trafficked locations. These findings support evidence from existing studies of the adverse health effects attributable to short-term exposures to TRAP.

\section{Author affiliations}

${ }^{1}$ Woolcock Institute of Medical Research, Sydney, New South Wales, Australia ${ }^{2}$ Cooperative Research Centre for Asthma and Airways, Sydney, Australia ${ }^{3}$ Commonwealth Scientific and Industrial Research Organisation, Newcastle, Australia

${ }^{4}$ NSW Health Department, Sydney, New South Wales, Australia

Acknowledgements We are grateful to the volunteers for their participation in this study. Professor Bert Brunekreef, Vicky Sheppeard and Michael Staff gave initial advice on the study design. We acknowledge the invaluable assistance of the following research staff: Brett Toelle, Elena Belousova, Adriana Cortes-Waterman, Kitty Ng, Angelica Ordonez, Paula Garay, Adrian Forero, Jennifer Manning, Renate Thielbeer. The study was overseen by a Scientific Advisory Group established by the NSW Health Department which provided advice on study design, methodology, analysis and interpretation. It consisted of Professor Bruce Armstrong, Professor Judy Simpson, Associate Professor Bin Jalaludin, Dr Peter Lewis and Dr Gavin Fisher

Contributors CC organised and participated in all aspects of the study including study design, ethics clearances, recruiting subjects, field work, statistical analysis and led manuscript preparation. WE was involved in all field work. WX contributed to study design and data analysis. WL conducted air quality exposure assessment measurements in the field and provided advice on air quality measurement. NR contributed biostatistical expertise. MR conducted air quality measurements in the field and wind rose analyses. GM participated in the study design, statistical analysis and provided general oversight of the study. All authors contributed to the preparation of the manuscript.

Funding The study was funded by the CRC for Asthma \& Airways and the NSW Health Department.

Competing interests Nectarios Rose was employed with the NSW Health Department on the Biostatistics Training Scheme at the time the study was conducted.

Patient consent The presented data are anonymised and risk of identification is low. 
Ethics approval University of Sydney Human Research Ethics Committee.

Provenance and peer review Not commissioned; externally peer reviewed.

Data sharing statement No additional data are available.

\section{REFERENCES}

1. NHMRC. Air quality in and around traffic tunnels. Final Report 2008. Commonwealth of Australia. ISBN online 1864963573. http://www. nhmrc.gov.au/guidelines/publications/eh42 (accessed 25 Feb 2011).

2. Kuykendall JR, Shaw SL, Paustenbach D, et al. Chemicals present in automobile traffic tunnels and the possible community health hazards: a review of the literature. Inhal Toxicol 2009;21:747-92.

3. Capon A, Sheppeard V, Irvine K, et al. Investigating health effects in a community surrounding a road tunnel stack - a cross sectional study. Environ Health 2008;7:10.

4. Jacobs L, Nawrot T, de Geus B, et al. Subclinical responses in healthy cyclists briefly exposed to traffic-related air pollution: an intervention study. Environ Health 2010;9:64.

5. McCreanor J, Cullinan P, Nieuwenhuijsen MJ, et al. Respiratory effects of exposure to diesel traffic in persons with asthma. $N$ Eng J Med 2007;357:2348-58.

6. Adar SD, Adamkiewicz G, Gold DR, et al. Ambient and microenvironmental particles and exhaled nitric oxide before and after a group bus trip. Environ Health Perspect 2007;115:507-12.

7. Strak M, Boogaard $\mathrm{H}$, Meliefste $\mathrm{K}$, et al. Respiratory health effects of ultrafine and fine particle exposure in cyclists. Occup Environ Med 2010;67:118-24.

8. Zuurbier M, Hoek G, Oldenwening M, et al. Respiratory effects of commuters' exposure to air pollution in traffic. Epidemiology 2011;22:219-27.

9. Adar SD, Gold DR, Coull BA, et al. Focused exposures to airborne traffic particles and heart rate variability in the elderly. Epidemiology 2007:18:95-103.

10. Dales R, Liu L, Szyszkowicz M, et al. Particulate air pollution and vascular reactivity: the bus stop study. Int Arch Occup Environ Health 2007:81:159-64.

11. Laumbach RJ, Rich DQ, Gandhi S, et al. acute changes in heart rate variability in subjects with diabetes following a highway traffic exposure. J Occup Environ Med 2010;52:324-31.

12. Zuurbier M, Hoek G, Oldenwening M, et al. In-traffic air pollution exposure and $\mathrm{CC} 16$, blood coagulation, and inflammation markers in healthy adults. Environ Health Perspect 2011;119:1384-9.

13. Weichenthal S, Kulka R, Dubeau A, et al. Traffic-related air pollution and acute changes in heart rate variability and respiratory function in urban cyclists. Environ Health Perspect 2011;119: 1373-8.

14. RTA. Annual Average Daily Traffic (AADT) data. Sydney Region, 2005. http://wwwrtanswgovau/trafficinformation/downloads/ aadtdata_dl1html (accessed 16 Dec 2010).
15. ISAAC. Worldwide variation in the prevalence of symptoms of asthma, allergic rhinoconjunctivitis, and atopic eczema: ISAAC Lancet 1998;351:1225-32.

16. Toelle $\mathrm{B}, \mathrm{Ng} \mathrm{K}$, Belousova $\mathrm{E}$, et al. The prevalence of asthma and allergy in schoolchildren in Belmont, Australia: three cross sectional surveys over 20 years. BMJ 2004:328:386-7.

17. Nordin S, Millqvist E, Lowhagen O, et al. A short chemical sensitivity Scale for assessment of airway sensory hyperreactivity. Int Arch Occup Environ Health 2004:77:249-54.

18. American Thoracic Society. ATS/ERS recommendations for the standardization procedures for the online and offline measurement of exhaled lower respiratory nitric oxide and nasal nitric oxide, 2005. Am J Respir Crit Care Med 2005;171:912-30.

19. Salome C, Roberts A, Brown N, et al. Exhaled nitric oxide in a population sample of young adults. Am J Respir Crit Care Med 1999;159:911-16.

20. Peat J, Mihrshahi S, Kemp A, et al. Three-year outcomes of dietary fatty acid modification and house dust mite reduction in the Childhood Asthma Prevention Study. J Allergy Clin Immunol 2004;114:807-13.

21. Team Ferrari Environmental. Audit of ambient air monitoring. Lane cove tunnel 2006. November 2006, NSW, Australia.

22. Nightingale JA, Maggs $\mathrm{R}$, Cullinan $\mathrm{P}$, et al. Airway inflammation after controlled exposure to diesel exhaust particulates. Am J Respir Crit Care Med 2000;162:161-6.

23. Nordenhall C, Pourazar J, Blomberg A, et al. Airway inflammation following exposure to diesel exhaust: a study of time kinetics using induced sputum. Eur Respir J 2000:15:1046-51.

24. Salvi S, Blomberg A, Rudell B, et al. Acute inflammatory responses in the airways and peripheral blood after short-term exposure to diesel exhaust in healthy human volunteers. Am J Respir Crit Care Med 1999;159:702-9.

25. Stenfors N, Nordenhall C, Salvi SS, et al. Different airway inflammatory responses in asthmatic and healthy humans exposed to diesel. Eur Respir J 2004;23:82-86.

26. Nordenhall C, Pourazar J, Ledin M-C, et al. Diesel exhaust enhances airway responsiveness in asthmatic subjects. Eur Respir J 2001;17:909-15.

27. Rudell B, Ledin MC, Hammarstrom U, et al. Effects on symptoms and lung function in humans experimentally exposed to diesel exhaust. Occup Environ Med 1996;53:658-62.

28. Gong H, Linn WS, Sioutas C, et al. Controlled exposures of healthy and asthmatic volunteers to concentrated ambient fine particles in Los Angeles, Inhal Toxicol 2003:15:305-25.

29. Hesterberg TW, Bunn WB, McClellan RO, et al. Critical review of the human data on short-term nitrogen dioxide $\left(\mathrm{NO}_{2}\right)$ exposures: evidence for $\mathrm{NO}_{2}$ no-effect levels. Crit Rev Toxicol 2009;39:743-81.

30. Larsson B-M, Grunewald J, Sköld CM, et al. Limited airway effects in mild asthmatics after exposure to air pollution in a road tunnel. Resp Med 2010;104:1912-18. 


\section{Correction}

Cowie CT, Ezz W, Xuan W, et al. A randomised cross-over cohort study of exposure to emissions from a road tunnel ventilation stack. BMJ Open 2012;2:e001201. Spacing in table 3 was inaccurate and missed some header rows. The corrected table is below. Also, in the third paragraph of the section entitled "Health outcomes" the sentence "... higher scores for EYE, CHEST and THROAT symptoms (last row, table 3)" should actually be "higher scores for EYE and CHEST symptoms (table 3)." In addition, the volume number should be listed as "2" in this article. We apologise for these errors.

BMJ Open 2012;2:e001201corr1. doi:10.1136/bmjopen-2012-001201corr1 


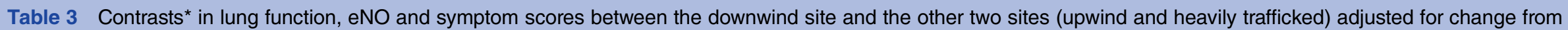
baseline (2006) to subsequent years

\begin{tabular}{|c|c|c|c|c|c|c|}
\hline \multicolumn{2}{|l|}{ Contrast* $^{\star}$} & \multirow{2}{*}{$\begin{array}{l}\text { FEV1 (diff in litres) } \\
\text { (95\% Cl) }\end{array}$} & \multirow{2}{*}{$\begin{array}{l}\text { FVC (diff in litres) } \\
(95 \% \mathrm{Cl})\end{array}$} & \multirow[b]{2}{*}{ eNO Ratio $(95 \% \mathrm{Cl})$} & \multirow{2}{*}{$\begin{array}{l}\text { EYE symptoms } \\
\text { (diff in score) } \\
(95 \% \mathrm{Cl})\end{array}$} & \multirow{2}{*}{$\begin{array}{l}\text { THROAT symptoms } \\
\text { (diff in score) } \\
(95 \% \mathrm{Cl})\end{array}$} \\
\hline Location & Year & & & & & \\
\hline \multirow{3}{*}{$\begin{array}{l}\text { Downwind vs (Heavily } \\
\text { trafficked and Upwind) }^{\dagger}\end{array}$} & $2007 / 08$ vs $2006^{\ddagger}$ & $0.01(-0.04-0.06)$ & $0.03(-0.03-0.09)$ & $1.03(0.94-1.12)$ & $-0.006(-0.097-0.086)$ & $0.130(-0.084-0.344)$ \\
\hline & 2007 vs 2006 & $0.03(-0.03-0.09)$ & $0.05(-0.03-0.13)$ & $1.01(0.91-1.11)$ & $-0.055(-0.159-0.049)$ & $0.041(-0.220-0.301)$ \\
\hline & 2008 vs 2006 & $-0.004(-0.07-0.06)$ & $0.02(-0.07-0.10)$ & $1.05(0.94-1.17)$ & $0.043(-0.074-0.159)$ & $0.207(-0.027-0.441)$ \\
\hline \multirow[t]{3}{*}{ Downwind vs Upwind } & $2007 / 08$ vs $2006^{\ddagger}$ & $0.02(-0.04-0.08)$ & $0.06(-0.02-0.13)$ & $1.03(0.93-1.14)$ & $-0.044(-0.151-0.063)$ & $0.080(-0.169-0.329)$ \\
\hline & 2007 vs 2006 & $0.04(-0.03-0.11)$ & $0.06(-0.03-0.15)$ & $1.05(0.94-1.17)$ & $-0.108(-0.229-0.012)$ & $-0.006(-0.308-0.297)$ \\
\hline & 2008 vs 2006 & $0.004(-0.07-0.08)$ & $0.06(-0.04-0.15)$ & $1.01(0.89-1.15)$ & $0.015(-0.120-0.149)$ & $0.179(-0.092-0.449)$ \\
\hline Downwind vs Heavily & $2007 / 08$ vs $2006^{\ddagger}$ & $-0.00(-0.06-0.06)$ & $0.004(-0.07-0.08)$ & $1.03(0.93-1.14)$ & $0.033(-0.073-0.140)$ & $0.180(-0.068-0.428)$ \\
\hline \multirow[t]{2}{*}{ trafficked } & 2007 vs 2006 & $0.02(-0.05-0.09)$ & $0.04(-0.05-0.12)$ & 0.97 (0.87-1.08) & $-0.002(-0.121-0.117)$ & $0.087(-0.212-0.385)$ \\
\hline & 2008 vs 2006 & $-0.01(-0.09-0.06)$ & $-0.03(-0.12-0.07)$ & 1.09 (0.96-1.23) & $0.071(-0.065-0.206)$ & $0.236(-0.038-0.509)$ \\
\hline $\begin{array}{l}\text { Heavily trafficked vs } \\
\text { (Upwind and } \\
\text { Downwind) } \\
\text { § }\end{array}$ & Overall & $-0.01(-0.04-0.01)$ & $-0.03(-0.06-0.002)$ & $1.09(1.04-1.14)$ & $0.054(0.006-0.102)$ & $0.107(-0.005-0.218)$ \\
\hline \multicolumn{2}{|l|}{ Contrast* } & \multirow{2}{*}{$\begin{array}{l}\text { CHEST symptoms } \\
\text { (diff in score) }(95 \% \mathrm{Cl})\end{array}$} & \multirow{2}{*}{$\begin{array}{l}\text { SNEEZE symptoms } \\
\text { (diff in score) }(95 \% \mathrm{CI})\end{array}$} & \multirow{2}{*}{$\begin{array}{l}\text { DRY NOSE symptoms } \\
\text { (diff in score) }(95 \% \mathrm{Cl})\end{array}$} & \multirow{2}{*}{$\begin{array}{l}\text { SMELL-STRONG } \\
\text { Odds ratio }(95 \% \mathrm{CI})\end{array}$} & \multirow{2}{*}{$\begin{array}{l}\text { SMELL-ANNOYING } \\
\text { Odds ratio }(95 \% \mathrm{CI})\end{array}$} \\
\hline Location & Year & & & & & \\
\hline Downwind vs (Heavily & $2007 / 08$ vs $2006^{\ddagger}$ & $-0.080(-0.302-0.142)$ & $0.288(-0.139-0.716)$ & $0.276(0.040-0.511)$ & $3.45(1.57-7.60)$ & $1.69(0.72-3.96)$ \\
\hline \multirow[t]{2}{*}{ trafficked and Upwind) ${ }^{\dagger}$} & 2007 vs 2006 & $-0.031(-0.277-0.214)$ & $0.375(-0.093-0.844)$ & $0.320(0.053-0.587)$ & $5.72(2.35-13.91)$ & $1.95(0.77-4.94)$ \\
\hline & 2008 vs 2006 & $-0.133(-0.409-0.143)$ & $0.182(-0.254-0.618)$ & $0.229(-0.057-0.516)$ & $2.14(0.77-5.97)$ & $1.33(0.44-4.00)$ \\
\hline \multirow[t]{3}{*}{ Downwind vs Upwind } & $2007 / 08$ vs $2006^{\ddagger}$ & $-0.017(-0.275-0.242)$ & $0.430(-0.067-0.927)$ & $0.193(-0.081-0.466)$ & $3.51(1.40-8.80)$ & $1.23(0.45-3.40)$ \\
\hline & 2007 vs 2006 & $0.033(-0.252-0.318)$ & $0.422(-0.123-0.966)$ & $0.187(-0.124-0.498)$ & $4.11(1.48-11.43)$ & $1.12(0.38-3.37)$ \\
\hline & 2008 vs 2006 & $-0.042(-0.362-0.277)$ & $0.424(-0.080-0.929)$ & $0.178(-0.154-0.510)$ & $3.31(0.98-11.18)$ & $1.26(0.34-4.71)$ \\
\hline \multirow{3}{*}{$\begin{array}{l}\text { Downwind vs Heavily } \\
\text { trafficked }\end{array}$} & $2007 / 08$ vs $2006^{\ddagger}$ & $-0.143(-0.400-0.114)$ & $0.147(-0.349-0.642)$ & $0.358(0.086-0.631)$ & 3.39 (1.39-8.29) & $2.31(0.90-5.94)$ \\
\hline & 2007 vs 2006 & $-0.096(-0.377-0.185)$ & $0.329(-0.208-0.866)$ & $0.453(0.146-0.759)$ & 7.96 (2.89-21.93) & $3.38(1.20-9.54)$ \\
\hline & 2008 vs 2006 & $-0.224(-0.547-0.099)$ & $-0.060(-0.570-0.450)$ & $0.281(-0.054-0.617)$ & $1.38(0.44-4.40)$ & $1.40(0.41-4.75)$ \\
\hline $\begin{array}{l}\text { Heavily trafficked vs } \\
\text { (Upwind and } \\
\text { Downwind })^{\S}\end{array}$ & Overall & $0.209(0.094-0.325)$ & $0.150(-0.072-0.372)$ & $0.022(-0.101-0.144)$ & $2.34(1.58-3.49)$ & $4.08(2.67-6.25)$ \\
\hline
\end{tabular}

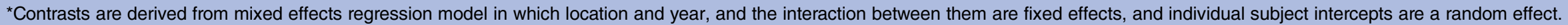

Main contrasts of interest are those included in the table and consist of downwind versus other exposures, as the downwind exposure is the primary exposure of interest in this study.

tDownwind vs (heavily trafficked and upwind) is the comparison of downwind versus heavily trafficked and upwind exposures combined.

$\ddagger_{2007 / 08}$ vs 2006 represents the comparison of both post-tunnel years combined (2007/08) versus the pre-tunnel year (2006).

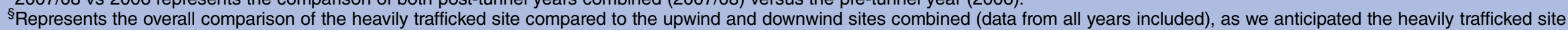
to have higher air pollution levels and that health effects would be more prominent. 